\title{
Analysis of major triterpene acids and total polysaccharides in the leaves of 11 species of Eriobotrya
}

\author{
Yanping Hong ${ }^{1}$, Biaosheng Lin ${ }^{1}$, Hongyun Cao ${ }^{1}$, Yongshun Gao ${ }^{1}$ and Shunquan $\mathrm{Lin}^{2, a}$ \\ ${ }^{1}$ College of Life Science, Longyan University, Longyan, Fujian 364012, China \\ ${ }^{2}$ College of Horticulture, South China Agricultural University, Guangzhou 510642, China
}

\begin{abstract}
Loquat (Eriobotrya japonica) is a subtropical tree with commercially important fruit and with leaves that have medicinal uses against cough and asthma. Leaves contain significant amounts of phenols, flavonoids, triterpene acids, and polysaccharides. However, information of the triterpene acids and polysaccharides in leaves is limited. In this study, the contents of five major triterpene acids and total polysaccharides in the leaves of 11 species of Eriobotrya were determined using RP-HPLC and phenol-sulfuric acid method, respectively. Total concentration of triterpene acids varied from 8.38 to $22.35 \mathrm{mg} \mathrm{g}-1 \mathrm{DW}$. The concentration of triterpene acids was greater than $20 \mathrm{mg}$ g-1 DW in E. bengalensis, E. prinoides and E. fragrans, and it was less than $10.0 \mathrm{mg} \mathrm{g}-1 \mathrm{DW}$ in E. elliptica. Different drying temperature $\left(40-80^{\circ} \mathrm{C}\right)$ of leaves did not affect the content of polysaccharides with highest content ( $80.8 \mathrm{mg}$ g-1 DW) from E. prinoides. The contents of triterpene acid in six wild species and polysaccharides in 5 wild species were higher than that in cultivated loquat.
\end{abstract}

\section{Introduction}

Dried leaves of loquat (Eriobotrya japonica (Thunb) Lindl.) have been used as a traditional Chinese medicine for the treatments of cough and asthma [1-2]. Most investigations on functional compounds in loquat leaves have been concentrated on only one species Eriobotrya japonica [3-9]There are a few studies on triterpene acids and polysaccharides [10].

Polysaccharides, which play an important role in the structural composition of living systems, are being identified via the processes of biological recognition, regulation, and information storage. In the last decades, some polysaccharides extracted from natural sources showed important biological activities, such as antitumor, immunomodulatory, hypoglycemic and anti-inflammatory and are attracting increasing attention in medicine. There are many investigations related to the viability of using ursolic acid as an effective medicine in anti-tumor treatment [11] and antifatigue agents [12].

\section{Material and methods}

\footnotetext{
${ }^{\text {a }}$ Corresponding author: kk9096@126.com

This work was supported by Guangdong Provincial Natural Science Foundation (Grant No. 07118121), Fujian Provincial Key Science and Technology Project (Grant No. 2012N0019), Fujian Provincial Natural Science Foundation (Grant No. 2012D100), Fujian Provincial Department of Education Project (Grant No. JB12204).
} 


\subsection{Materials}

Mature leaves were obtained from 11 species of Eriobotrya trees grown in the orchard in South China Agriculture University. Leaves were dried for 3-4 days at about $40{ }^{\circ} \mathrm{C}$, and then crushed into powder ( 80 mesh). The ground powder was stored at about $-20^{\circ} \mathrm{C}$ prior to analysis. The 12 samples of 11 species used in this study are listed in Table 1.

Table 1. The contents of triterpene acid (mg/g powder) and polysaccharide ( amount to glucose $\mathrm{mg} / \mathrm{g} \mathrm{DW}$ ) in various species of Eriobotrya.

\begin{tabular}{|c|c|c|c|c|c|c|c|c|}
\hline Species & English name & A & B & $\mathrm{C}$ & $\mathrm{D}$ & $\mathrm{E}$ & $\begin{array}{l}\text { The content of } \\
\text { triterpene acid }\end{array}$ & $\begin{array}{l}\text { The content of } \\
\text { polysaccharide }\end{array}$ \\
\hline $\begin{array}{l}\text { E. japonica cv. } \\
\text { Zaozhong No. } 6\end{array}$ & $\begin{array}{c}\text { Common } \\
\text { loquat cv. } \\
\text { Zaozhong } 6\end{array}$ & 3.13 & 1.47 & 1.02 & 1.90 & 7.35 & 14.88 & $42.83 \pm 2.05 \mathrm{e}$ \\
\hline E. japonica Lindl. & $\begin{array}{l}\text { Common } \\
\text { loquat (wild } \\
\text { tree) }\end{array}$ & 2.50 & 0.64 & 0.50 & 1.69 & 5.57 & 10.90 & $44.97 \pm 1.66 \mathrm{e}$ \\
\hline E. elliptica Lindl. & Tibet loquat & 3.34 & 1.23 & 0.81 & - & 3.01 & 8.38 & $45.39 \pm 1.95 \mathrm{e}$ \\
\hline $\begin{array}{l}\text { E. prinoides var. } \\
\text { dadunensis }\end{array}$ & Daduhe loquat & 3.81 & 1.13 & 0.83 & 1.44 & 9.20 & 16.41 & $60.24 \pm 3.00 \mathrm{c}$ \\
\hline $\begin{array}{c}\text { E. prinoides Rehd } \\
\text { \& Wils }\end{array}$ & $\begin{array}{l}\text { Oak leaf } \\
\text { loquat }\end{array}$ & 2.04 & 5.25 & 1.27 & 2.31 & 9.53 & 20.40 & $80.79 \pm 0.72 \mathrm{a}$ \\
\hline E. deflexa Nakai & Taiwan loquat & 2.11 & 1.52 & 0.61 & 1.30 & 5.86 & 11.40 & $45.23 \pm 0.33 \mathrm{e}$ \\
\hline $\begin{array}{l}\text { E. deflexa } \text { var. } \\
\text { koshunensis }\end{array}$ & $\begin{array}{l}\text { Hengchun } \\
\text { loquat }\end{array}$ & 1.51 & 1.79 & 0.86 & 1.36 & 9.73 & 15.25 & $42.88 \pm 0.55 \mathrm{e}$ \\
\hline $\begin{array}{l}\text { E. fragrans } \\
\text { Champ }\end{array}$ & $\begin{array}{c}\text { Fragrant } \\
\text { loquat }\end{array}$ & 1.53 & 5.76 & 0.98 & 2.81 & 9.13 & 20.21 & $72.68 \pm 3.23 b$ \\
\hline $\begin{array}{l}\text { E. kwangsiensis } \\
\text { Chun }\end{array}$ & $\begin{array}{l}\text { Guangxi } \\
\text { loquat }\end{array}$ & 2.25 & 4.14 & 0.41 & 0.96 & 5.17 & 12.93 & $41.78 \pm 1.51 \mathrm{ef}$ \\
\hline $\begin{array}{l}\text { E. bengalensis } \\
\text { Hook. f. }\end{array}$ & Bengal loquat & 1.89 & 3.20 & 0.80 & 2.46 & 14.01 & 22.35 & $54.28 \pm 2.70 \mathrm{~d}$ \\
\hline $\begin{array}{l}\text { E. obovata W. W. } \\
\text { Smith }\end{array}$ & $\begin{array}{c}\text { Obovata leaf } \\
\text { loquat }\end{array}$ & 2.91 & 5.64 & 0.51 & - & 3.57 & 12.63 & $41.94 \pm 1.95 \mathrm{ef}$ \\
\hline E. cavaleriei Rehd & $\begin{array}{l}\text { Big flower } \\
\text { loquat }\end{array}$ & 2.97 & 4.87 & 1.04 & 1.42 & 8.69 & 18.99 & $55.90 \pm 1.19 \mathrm{~d}$ \\
\hline
\end{tabular}

Note: 1. A: tormentic acid; B: $2 \alpha, 19 \alpha$-dihydroxy-3-oxo-urs-12-en-28-oic acid;

C: $2 \alpha$-hydroxyoleanolic acid; D: oleanolic acid; E: ursolic acid

2. Meaning with different letters within the same column are significantly different at the level of $5 \%$.

\subsection{Sample Preparation and HPLC Analysis of triterpene acid}

Sample preparation and HPLC analysis were carried out according to $\mathrm{Ju}$ et al [4]. with some modifications: $0.8 \mathrm{~g}$ dried powder was suspended in $20 \mathrm{~mL}$ chloroform and exposed to ultrasonic twice, each for $20 \mathrm{~min}$, with an interval of $10 \mathrm{~min}$. The suspension was kept over night (about $12 \mathrm{~h}, 25^{\circ} \mathrm{C}$ ), and then recovered to its original volume followed by filtration; $5 \mathrm{~mL}$ filtrate was dried and dissolved in $5 \mathrm{~mL}$ of methanol. The solution was filtered through a membrane with a pore size of $0.22 \mu \mathrm{m}$.

Filtrate $(20 \mu \mathrm{L})$ was injected into the HPLC apparatus, which is consist of an Aglien HP1100 quaternary HPLC pump system with VWD system, a SK5200H (200W) ultrasonic launder and a Laborata 4000 (Heidolph) evaporator. The column was $5 \mu \mathrm{m}$ hypersil ODS2 (250 mm * $4.6 \mathrm{~mm}$ I.D.) in $25{ }^{\circ} \mathrm{C}$. The mobile phase was a solution composed of acetonitrile, methanol and $21 \mathrm{mg} \mathrm{mL}^{-1}$ aqueous solution of ammonium acetate (v:v:v=60: 14: 26), with a flow rate at $1.5 \mathrm{ml} \mathrm{min} \mathrm{m}^{-1}$. The detector wavelength was $215 \mathrm{~nm}$. 
Ursolic acid and oleanolic acid were provided by the National Institute for the Control of Pharmacerticals and Biological Products (Beijing, China), and tormentic acid, $2 \alpha, 19 \alpha$-dihydroxy-3oxo-urs-12-en-28-oic acid, 2 $\alpha$-hydroxyoleanolic acid (maslinic acid) were isolated from Fragrent loquat[8], all these were used as standard. Methanol and acetonitrile were of chromatographic purity and all the other chemicals used were of analytical purity. All the aqueous solutions were prepared with double distilled water and filtered through $0.45 \mu \mathrm{m}$ nylon filters before use. Data was acquired and analyzed using Aglien Chem Stations.

\subsection{Sample preparation and determination of polysaccharides contents}

\subsubsection{Orthogonal assay of polysaccharides extraction}

Three factors and three-level orthogonal test were carried out to determine the optimum extraction method of polysaccharides. The dried powder of 'Zaozhong 6' loquat were firstly defatted with ethanol solution and the resulting residues were suspended in deionized water of different volumn (Solid-liquid ratio were $1: 10,1: 15,1: 20$ ), and then treated for $3 / 6 / 9$ hours by warm water bath (temperature were $60{ }^{\circ} \mathrm{C}, 80{ }^{\circ} \mathrm{C}, 100{ }^{\circ} \mathrm{C}$ ), after that, the supernatant were collected for the analysis of polysaccharides by phenol - vitriolic colorimetry.

\subsubsection{Dried temperature}

Leaves of 'Zaozhong 6' loquat were dried in three temperatures $\left(40^{\circ}, 60^{\circ}\right.$ and $\left.80^{\circ} \mathrm{C}\right)$ for $3-4$ days.

\subsubsection{Determination of polysaccharides contents}

The dried powder $(0.5 \mathrm{~g})$ of leaves from each species was firstly defatted in $20 \mathrm{~mL}$ of $50 \%$ ethanol solution by ultrasonic treatment, with $20 \mathrm{~min}$, using an ultrasonic instrument (SK5200H Ultrasonic Launder, 200 W, Kedao Supersonic Equipment Co. Ltd., Shanghai, China). The residues were suspended in $10 \mathrm{~mL}$ of deionized water, and then treated for 3 hours by boiling water bath, after that, the suspension were centrifuged at $12000 \mathrm{~g}$ for $15 \mathrm{~min}$.

The contents of polysaccharides of the supernatant were determined by phenol-vitriolic colorimetry. Firstly, $975 \mu \mathrm{L}$ deionized water was added to $25 \mu \mathrm{L}$ supernatant of each samples for diluting extraction, then $0.4 \mathrm{~mL}$ of $5 \%$ phenol was added to $0.2 \mathrm{~mL}$ of each diluted samples, after that, $2 \mathrm{~mL}$ of sulfuric acid was added immediately. The mixed solution was shaken vigorously under room temperature (about $25^{\circ} \mathrm{C}$ ) for $30 \mathrm{~min}$. The absorption was measured at $490 \mathrm{~nm}$, using distilled water as a blank. The amount of polysaccharides was measured and expressed as glucose equivalent (GE) on dry weight basis.

\subsubsection{Data analysis}

Each experiment was repeated by three times. The data were analyzed using the statistical package SPSS 10.0. Significant differences were calculated according to the Duncan's Multiple range test. Differences at the level of 5\% were considered as statistically significant.

\section{Results and discussion}

\subsection{Quantitative determination of triterpene acid}

The samples of 'Zaozhong No.6' and ursolic acid were used for precision test, reproducibility test, recovery test and stability test. The results showed the method of HPLC was credible[6]. 
A series of solutions of tormentic acid, $2 \alpha, 19 \alpha$-dihydroxy-3-oxo-urs-12-en-28-oic acid, $2 \alpha$ hydroxyoleanolic acid (maslinic acid), oleanolic acid and ursolic acid at gradient concentrations were prepared in methanol. The standard curve of concentration vs peak area was established. All the standard curves fitted perfect linear equation.

tormentic acid: $\mathrm{Y}=5.46827479 \mathrm{X}+10.15579(\mathrm{r}=0.99954)$;

$2 \alpha, 19 \alpha$-dihydroxy-3-oxo-urs-12-en-28-oic acid: $\mathrm{Y}=3.99517844 \mathrm{X}+4.5830234(\mathrm{r}=0.99967)$;

$2 \alpha$-hydroxyoleanolic acid: $\mathrm{Y}=5.855837 \mathrm{X}+40.010592(\mathrm{r}=0.99954)$;

oleanolic acid: $\mathrm{Y}=5.3474258 \mathrm{X}+9.7835004(\mathrm{r}=0.99955)$;

ursolic acid: $\mathrm{Y}=4.33280277 \mathrm{X}+19.362927(\mathrm{r}=0.99969)$.

The concentration of triterpene acids in different species of Eriobotrya varied from 8.38 to 22.35 $\mathrm{mg} \mathrm{g}^{-1} \mathrm{DW}$ (table 1). Triterpene acids concentration was higher than $20.0 \mathrm{mg} \mathrm{g}^{-1} \mathrm{DW}$ in Bengal loquat, Oak leaf loquat and Fragrant loquat, while it was lower than $10.0 \mathrm{mg} \mathrm{g}^{-1} \mathrm{DW}$ in Tibet loquat. The content of triterpene acids in 6 species were higher than the normal loquat, it suggested that these wild species could be better candidate materials for utilizing triterpene acids.

\subsection{Quantitative Determination of polysaccharides}

\subsubsection{Standard curve of glucose}

A series of solutions of glucose which were dried to constant weight at gradient concentrations $(40,80$, 120,160 and $200 \mu \mathrm{g} / \mathrm{mL}$ ) were prepared in deionized water. The OD490nm of those solutions were determined using phenol-vitriolic colorimetry. The standard curve of concentration vs OD490 nm was established. The standard curve fitted a perfect linear equation: $\mathrm{Y}=0.0051 \mathrm{X}-0.0047(\mathrm{r}=0.999)$.

\subsubsection{Orthogonal test of extraction}

Polysaccharides were determined for 9 different treatments (Table 2). The analysis of variance results showed that the temperature of water bath and the Solid-liquid ratio influenced the yield of polysaccharides, the optimum condition was boiling water bath $\left(100^{\circ} \mathrm{C}\right)$ for 3 hours using a Solid: liquid ratio of 1:20.

Table 2. The result of orthogonal test of polysaccharid extraction.

\begin{tabular}{ccccc}
\hline No. & $\begin{array}{c}\text { Temperature of water bath } \\
\left({ }^{\circ} \mathrm{C}\right)\end{array}$ & Solid-liquid ratio & $\begin{array}{c}\text { Time } \\
\text { (hours) }\end{array}$ & $\begin{array}{c}\text { Content of polysaccharide } \\
(\mathrm{mg} \text { GE /g DW) }\end{array}$ \\
\hline 1 & 60 & $1: 10$ & 3 & 10.448 \\
2 & 60 & $1: 15$ & 6 & 17.176 \\
3 & 60 & $1: 20$ & 9 & 21.776 \\
4 & 80 & $1: 10$ & 6 & 18.089 \\
5 & 80 & $1: 15$ & 9 & 23.343 \\
6 & 80 & $1: 20$ & 3 & 26.759 \\
7 & 100 & $1: 10$ & 9 & 23.670 \\
8 & 100 & $1: 15$ & 3 & 34.410 \\
9 & 100 & $1: 20$ & 6 & 36.895 \\
\hline
\end{tabular}

\subsubsection{Dried temperature and the contents of polysaccharides}

The leaves of 'Zaozhong 6' loquat were dried in three temperatures $\left(40^{\circ}, 60^{\circ}\right.$ and $\left.80^{\circ} \mathrm{C}\right)$ and the content of polyssachrids was $42.83 \pm 2.05 \mathrm{mg} \mathrm{GE} / \mathrm{g} \mathrm{DW}, 45.97 \pm 2.23 \mathrm{mg} \mathrm{GE} / \mathrm{g} \mathrm{DW}$ and $40.95 \pm 1.65 \mathrm{mg}$ 
GE/g DW respectively, the analysis of variance showed that the dried temperature had no apparent affect on the content of polysaccharides.

\subsubsection{Determination of the contents of polysaccharides}

Oak leaf loquat had the highest content of polysaccharaides $(80.79 \mathrm{mg} \mathrm{GE} / \mathrm{g} \mathrm{DW}, \mathrm{p}=0.05)$, followed by Fragrant loquat, Daduhe loquat, Big flower loquat and Bengal loquat (Table 1). The lowest amount of polysaccharides $(\mathrm{p}=0.05)$ was observed in Guangxi loquat and Obovata leaf loquat. The contents of the polysaccharides of 5 species were higher than those of the normal loquat. This indicates that there is a significant difference in polysaccharides content among the 11 Eriobotrya species. Therefore, rather than the normal loquat, some wild species could be identified as better material for utilizing the polysccharides from the leaves.

\section{Conclusion}

The contents of triterpene acid and polysaccharides in the leaves of Oak leaf loquat, Fragrant loquat, Daduhe loquat, Big flower loquat and Bengal loquat were higher than those of the normal loquat while Oak leaf loquat, Daduhe loquat, Big flower loquat and Bengal loquat contained significantly higher level of total phenolics and flavonoids, and had stronger antioxidant activities compared with those of the cultivated species'Zaozhong 6' loquat [7]. It is reported that, the contents of polysaccharides and flavones in old leaves were quiet different between different loquat cultivars [13]. Our research also showed that the contents of polysaccharides, triterpene acid and flavones in leaves differed significantly among different species of Eriobotyra. Our study suggests that high level of functional components may be found in wild species of loquat and could be useful for medicinal use.

\section{References}

1. S.Q. Lin, Acta. Hort. 750, 37-44 (2007).

2. J.Y. Lin, C.Y.Tang, Food Chem. 107, 1587-1596 (2008).

3. D.O. Gray, Phytochem. 11, 751-756 (1972).

4. J.H. Ju, L. Zhou, G. Lin, D.Liu, L.W. Wang, J.S. Yang, Chin. Pharm. J. 38, 752-757 (2003).

5. T.H. Lee, S.S.Lee, Y.C.Kuo, C.H. Chou, J. Nat. Prod. 64, 865-869 (2001).

6. Y.P. Hong, S.Q.Lin, X.M. Huang, Acta. Hort. 750, 225-232 (2006).

7. Y.P. Hong, S.Q.Lin, Y.M.Jiang, M. Ashraf, Plant Foods Hum. Nutr. 63,200-204 (2008a).

8. Y.P. Hong, Y.C. Qiao, S.Q.Lin, Y.M Jiang, F.Chen, Sci. Hort. 118, 288-292(2008b).

9. K. Kobaa, A.Matsuokab, K.Osadac, Y.S. Huangd, Food Chem. 104, 308-316 (2007).

10. G. F.Duan, B.Y. Yu, R. B.Wu, M.Q. Chen, B. J.Li, W. Chen, Chin. J. Stra. Pharm. J. 21, 50-53 (2009).

11. J. Huang, Y. Sun, China New Med. J. 6,101-104 (1997).

12. A. P. Huang, H.Y.Gao, X.P.Chen, T. Li, S.Q. Zhen, Chin. J. Fujian Fruit 137, 13-14(2006).

13. F. Jiang, S.Q.Zheng, H.Y.Gao, A.P. Huang, X.P.Chen, Acta. Hort., 750, 321-323 (2007). 